\title{
BULLOUS ERYTHEMA NODOSUM AS INITIAL MANIFESTATION OF LEPROSY
}

Carlos Antônio Gusmão Guerreiro Moura', Raphael Sampaio², Paulo Góes ${ }^{3}$, Gabriel de Magalhães Freitas ${ }^{4}$, Constança Margarida Sampaio $\mathrm{Cruz}^{5}$, Carlos Geraldo Guerreiro Moura ${ }^{6}$

'MD. Preceptor of the Residence of the Medical Clinic of the Santo Antonio's Hospital, Irmã Dulce's Social Works, and Professor at BAHIANASchool of Medicine and Public Health. Salvador, Bahia, Brazil. caggmoura@yahoo.com.br ${ }^{2}$ MD. Member of the Residence of the Medical Clinic of the Santo Antonio's Hospital, Irmã Dulce's Social Works. Salvador, Bahia, Brazil. rrsampaio@outlook.com

${ }^{3}$ MD. Member of the Residence of the Medical Clinic of the Santo Antonio's Hospital, Irmã Dulce's Social Works. Salvador, Bahia, Brazil. paulomgoes@gmail.com ${ }^{4}$ Undergraduate student at BAHIANA - School of Medicine and Public Health. Salvador, Bahia, Brazil. gabrielfreitas13.2@bahiana.edu.br ${ }^{5} \mathrm{MD}, \mathrm{PhD}$ in Medicine and Human Health. Professor at BAHIANA- School of Medicine and Public Health. Salvador, Bahia, Brazil. constancacruz@yahoo.com.br

${ }^{\circ} \mathrm{MD}, \mathrm{PhD}$ in Medicine and Human Health. Preceptor of the Residence of the Medical Clinic of the Santo Antonio's Hospital, Irmã Dulce's Social Works and Professor at BAHIANA - School of Medicine and Public Health. Salvador, Bahia, Brazil. carlosggmoura@gmail.com

\begin{abstract}
Introduction: Leprosy is a chronic granulomatous infectious disease caused by Mycobacterium leprae with protean manifestations, particularly prone to affect skin and peripheral nerves. The natural course of the disease may be associated with the development of type 1 or type 2 immunologic reactions. These immunologic reactions are reported to be caused by increased activity of the immune system, particularly a cell-mediated immune response against live leprosy bacillus or remnants of dead bacilli. Leprosy is one of the oldest diseases of mankind. Its clinical diagnosis can be challenging due to the varied manifestations. The first description of bullous erythema nodosum was made 1898 and since then there are few recorded reports. Case Report: Here we present a case of bullous erythema nodosum as leprosy first manifestation. A 35 year-woman presented with 1-year history of disseminated blisters on trunk, forearms and thighs, and multiple painful ulcerated nodules on her face. She reported that the lesions in her face became eroded and ulcerated spontaneously. There were no thickened nerves. Blood and Histopathological investigations were made. The treatment instituted was prednisone $1 \mathrm{mg} / \mathrm{kg}$ without thalidomide. After two weeks with excellent response, specific therapy for Mycobacterium leprae was initiated by the infectious diseases assistant physician with a satisfactory response.
\end{abstract}

Key words: Hansen disease, leprosy, mycobacterium, Bullous erythema nodosum 


\section{INTRODUCTION}

Leprosy is a chronic granulomatous infectious disease caused by Mycobacterium leprae with protean manifestations, particularly prone to affect skin and peripheral nerves. The natural course of the disease may be associated with the development of type 1 or type 2 immunologic reactions. These immunologic reactions are reported to be caused by increased activity of the immune system, particularly a cellmediated immune response against live leprosy bacillus or remnants of dead bacilli'. Although such reactions are reported to be more common during anti-mycobacterial treatment, they can sometimes be described as the first manifestations of disease'.

Type 2 reaction (T2R) predominantly occurs in patients with lepromatous (multibacillary) disease. It is characterized by systemic manifestations like arthralgia, fever, iridocyclitis, nephritis, myositis and lymphadenitis associated with eruption of numerous disseminated painful nodules characterized by erythema nodosum (EN) $)^{1,2}$. Although $\mathrm{EN}$ is considered the typical lesion of $T 2 R$, it may mimic diverse other clinical conditions, and in such cases, delays in diagnosis are commonly observed ${ }^{3-10}$. Bullous Erythema Nodosum Leprosum (BENL) is a subset of EN wich is a subset of EN which is manifested as disseminated bullous reactions. This manifestation is very rare, with only a few cases reporting such disease spectrum ${ }^{3,7-14}$.

In the present report, we present an unusual case of BENL as initial manifestation of leprosy, discussing clues to reach the correct diagnosis.

\section{CASE REPORT}

A 35 year-woman presented with 1-year history of disseminated blisters on trunk, forearms and thighs, and multiple painful ulcerated nodules on her face. She reported that the lesions became eroded and ulcerated spontaneously. She denied any mucous lesions, pruritus, pustules or desquamation. She also reported paresthesia on feet initiated 3 months before admission, as well as low-grade fever, symmetric polyarthritis (wrist, knee and ankles) and diffuse myalgia. She related no comorbidities and denied use of any medications or previous allergy history. Examination revealed disseminated symmetric blisters, predominantly on thighs and forearms, infiltrated ears, asymmetric loss of eyelash and ulcerated facial lesions (Figure 1). Mucosal membranes were not affected. Nikolsky and AsboeHansen signs were negative. "Puffy hands" and symmetric ankle arthritis were noted. Neurologic examination was evident for loss of sensory perception although with no deformities or motor deficits on plantar surface.There were no thickened nerves.
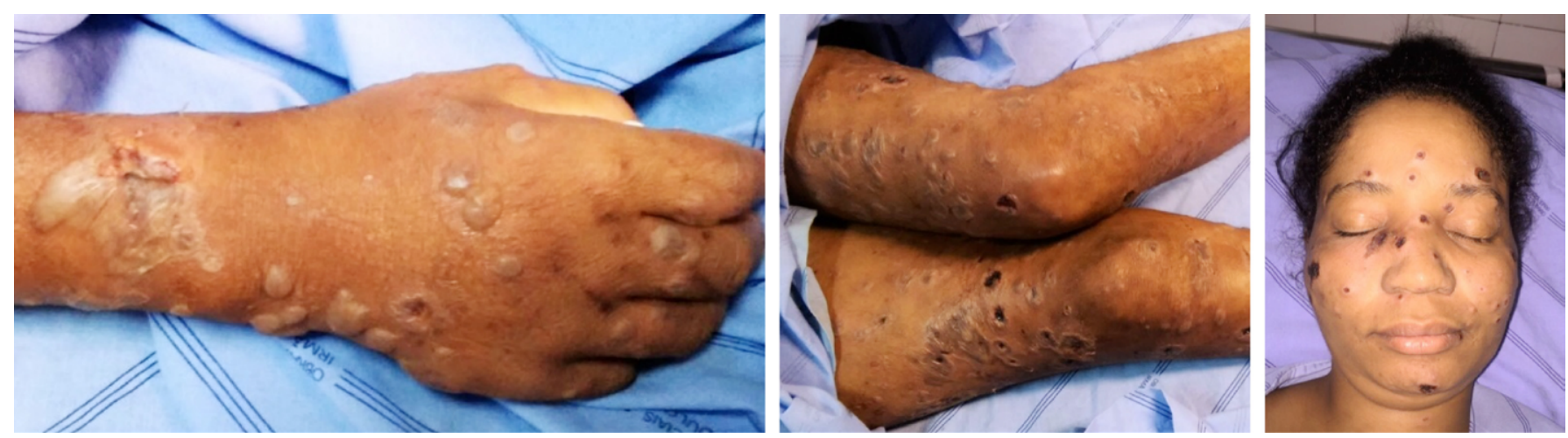

Figure 1. Dermatological findings.

Disseminated symmetric blisters on forearms (left panel) and thighs (central panel). Infiltrated ear, asymmetric loss of eyelash and ulcerated facial lesions (right panel). 




Figure 2: Histopathology findings.

(A) Lymphohistiocytic infiltration and foamy macrophages.

(B) Presence of acid-fast bacilli on Ziehl-Neelsen staining without signs of vasculitis.

\section{DISCUSSION}

Erythema nodosum leprosum is a common manifestation of T2R mediated by immune complexes, which occurs mainly in the lepromatous polo of leprosy ${ }^{3}$. Although the presence of bullous lesions is well-documented in the rare Lucio's phenomenon/ Erythema necroticans, this spectrum of lesion is even more uncommon in the classical ENL ${ }^{4-6}$. Probably the first description of bullous erythema nodosum was made by Gibb \& Aberd in $1898^{7}$ and since then there are few countable recorded reports.

Bullous erythema nodosum leprosum may easily be confounded by other blister diseases, especially considering its rarity, and must be included in the differential diagnosis of vesicle-bullous lesions. It is essential to rule out bullous drug eruptions, Sweet's syndrome ${ }^{8-10}$, pemphigus vulgaris, bullous pemphigoid and other syndromes ${ }^{11,12}$.

Although the physiopathology is not well understood, it has been postulated that a high bacterial load could lead to vasculitis and tumor necrosis factoralfa secretion leading to bullous lesions ${ }^{13}$.

Prominent vasculitis is a feature of BENL, but this matter is still in debate, since some patients have not histopathology findings consistent with vasculitis ${ }^{13}$.

Intradermal or subepidermal bulla, dermal edema, or leukocytoclastic vasculitis with polymorphonuclear infiltrate and foamy histiocytic lesions are the histopathologic finding prototype of $B E N L^{13}$.

Treatment of choice for T2R is a combination of thalidomide and corticosteroids. Unfortunately thalidomide teratogenicity limits its use in women in childbearing age, such as the patients reported here. For this reason, other immunosuppressive drugs have been tested in the treatment of type 2 reactions, including azathioprine and cyclosporine, but no beneficial results have been consistently observed ${ }^{15}$.

To the best of our knowledge, this is a rare case of BENL as an initial manifestation of leprosy. Despite its rarity, clinicians must include this entity in the hall of vesicle-bullous lesions. A detail that can help clinical judgment is that BENL generally does not affect mucosal tissues and it is strongly associated with nodules, an uncommon finding in others bullous disease.

\section{AUTHOR CONTRIBUTIONS}

Moura CAG, Moura CGG and Cruz CMS participated in the Study conception, the drafting of manuscript and the critical revision. Sampaio R, Góes $P$ and Freitas GM participated in the drafting of manuscript and the critical revision. 


\section{COMPETING INTERESTS}

No financial, legal or political competing interests with third parties (government, commercial, private foundation, etc.) were disclosed for any aspect of the submitted work (including but not limited to grants, data monitoring board, study design, manuscript preparation, statistical analysis, etc.).

\section{REFERENCES}

1. Talhari C, Talhari S, Penna GO. Clinical aspects of leprosy. Clin Dermatol. 2015;33(1):26-37. doi: 10.1016/i. clindermatol.2014.07.002

2. Lastoria JC, Abreu MA. Leprosy: review of the epidemiological, clinical, and etiopathogenic aspects - part 1. An Bras Dermatol. 2014;89(2):205-18. doi: 10.1590/ abd1 $806-4841.20142450$

3. Rijal A, Agrawal S, Agarwalla A, Lakhey M. Bullous erythema nodosum leprosum: a case report from Nepal. Lepr Ver. $2004 ; 75(2): 177-80$.

4. Jurado F, Rodriguez O, Novales J, Navarrete G, Rodriguez M. Lucio's leprosy: a clinical and therapeutic challenge.

Clin Dermatol. 2015;33(1):66-78. doi: 10.1016/i. clindermatol.2014.07.004

5. Kaur C, Thami GP, Mohan H. Lucio phenomenon and Lucio leprosy. Clin Exp Dermatol. 2005;30(5):525-7. doi: 10.1111/i.1365-2230.2005.01860.x

6. Sehgal VN. Lucio's phenomenon/erythema necroticans. Int J Dermatol. 2005;44(7):602-5. doi: $10.1111 /$ i.13654632.2005.02567.x

7. Gibb JA, Aberd CM. A case of erythema nodosum et bullosum. Lancet. 1898;151(3895):1 113. doi: 10.1016/ S0140-6736(01)77361-8

8. Heng YK, Chiam YT, Giam YC, Chong WS. Lepromatous leprosy in erythema nodosum leprosum reaction mimicking Sweet's syndrome. Int J Dermatol. 201 1; 50(9): 11 24-5. doi: 10.1111/i.1365-4632.2010.04686.x

9. Chiaratti FC, Daxbacher EL, Neumann AB, Jeunon T. Type 2 leprosy reaction with Sweet's syndrome-like presentation. An Bras Dermatol. 2016;91(3):345-9. doi: 10.1590/abd1806$\underline{4841.20164111}$

10. Bakshi N, Rao S, Batra R. Bullous Erythema Nodosum Leprosum as the First Manifestation of Multibacillary Leprosy: A Rare Phenomenon. Am J Dermatopathol. 2017;0(0):1-3. doi: $10.1097 /$ DAD.0000000000000887

11. Pradhan S, Prasad Nayak B, Padhi T, Sethy M. Bullous
Erythema Nodosum Leprosum masquerading as systemic onset juvenile idiopathic arthritis: A case report. Lepr Rev. 2015;86(4):387-90.

12. Vashisht $D$, Das AL. Bullous erythema nodosum leprosum. Med J Armed Forces India. 2013;69(1):71-3. doi: 10.1016/i. miafi.2012.02.010

13. Goyal T, Varshney A, Sharma V, Zawar V. A rare case of facial annular bullous erythema nodosum leprosum reaction in a young boy. Int J Dermatol. 2016;55(6):e368-71. doi: $\underline{10.1111 / \mathrm{ijd} .13221}$

14. Pocaterra L, Jain S, Reddy R, Muzaffarullah S, Torres $O$, Suneetha $S$ et al. Clinical course of erythema nodosum leprosum: an 11 -year cohort study in Hyderabad, India. Am J Trop Med Hyg. 2006;74(5):868-79.

15. Scollard DM, Adams LB, Gillis TP, Krahenbuhl JL, Truman RW, Williams DL. The continuing challenges of leprosy. Clin Microbiol Rev. 2006;19(2):338-81. doi: 10.1128/ CMR.19.2.338-381.2006 